\title{
Destino turístico e hospedagem: 0 papel das agências de viagens e dos operadores de turismo
}

Suzana Rodrigues Macedo. Mestre em Meteorologia. Faculdade de Tecnologia Senac Florianópolis - Brasil. suzana@prof.sc.senac.br Fabiane Rosana da Silva. Mestre em Comunicação. Faculdade de Tecnologia Senac Florianópolis - Brasil. silvafabiane887@gmail.com

\section{RESUMO}

O presente trabalho teve como objetivo inicial, realizar uma ampla análise a respeito de como as agências de viagens e operadoras turísticas têm influenciado na escolha dos meios de hospedagens por parte dos hóspedes em Santa Catarina. Muitos turistas utilizam-se das informações prestadas por estes e por outros intermediários para planejar suas viagens, mas acabam optando por realizar reservas em contato direto com o meio de hospedagem. No entanto, para avaliar esta realidade, contamos com uma amostra de meios de hospedagens em Santa Catarina no ano de 2015, cujo tamanho limitou as conclusões mas permitiu análises preliminares, indicando a necessidade de novos estudos a respeito da influência das agências e operadoras, através de uma fragmentação por tipo de meio de hospedagem, pois esta influência parece estar relacionada ao porte do empreendimento.

Palavras-chave: Turismo Santa Catarina. Agências de viagens. Operadoras turísticas.

\section{Tourist destination and accommodation: the role of travel agencies and tour operators}

\begin{abstract}
This research had as the initial goal, to conduct a comprehensive analysis on how the travel agencies and tour operators have influenced the choice of accommodation by the guests in Santa Catarina. Many tourists use the information provided by agencies, operators and other intermediaries to plan their trips, but end up choosing to make reservations contacting with the means of accommodation directly. However, to assess this reality, we had as sample the year 2015 means of accommodation in the region whose size has limited the conclusions of the research. It allowed, however, a preliminary analysis, indicating the need for further studies on the influence of agencies and operators, through a fragmentation by the type of accommodation, as this influence appears to be related to the size of the enterprise.
\end{abstract}

Keywords: Santa Catarina tourism. Travel agencies. Tour operators. 


\section{INTRODUÇÃO}

Os intermediários turísticos, agências e operadores turísticos têm como principal função disponibilizar os serviços realizados por fornecedores primários aos consumidores finais. Esta comercialização pode se dar de forma isolada, por meio da aquisição de serviços individuais, ou mediante reunião de serviços diversos em pacotes. Até pouco tempo, esses intermediadores eram vistos pelos consumidores finais como principais facilitadores na aquisição e organização de serviços turísticos. No entanto, estudos como os de Buhalis (2003), Buhalis e Law (2008), Tomelin (2001; 2011), Tomelign e Teixeira (2005), Gosson et al (2014) apontam mudanças estruturais nos canais de distribuição do turismo, destacando a desintermediação - decorrente da evolução do comércio eletrônico e do acesso às informações sobre produtos turísticos por meio da internet - e a verticalização - tendência de os operadores turísticos comprarem agências de viagens para reforçar sua posição no mercado. Estes autores alertam, por exemplo, para a tendência de diminuição do poder de comércio dos intermediadores turísticos, devido ao impacto da evolução tecnológica da informação. Uma vez que é crescente a disponibilização de informações turísticas e sobre serviços na internet, é razoável considerar que o turista pode, atualmente, encontrar por meio de recursos eletrônicos, seus destinos, hospedagens, aluguéis de serviços de forma privada, organizando assim, o próprio pacote turístico.

No entanto, as agências de viagem e os operadores turísticos se constituem como intermediários importantes da cadeia produtiva, um elo que aproxima os turistas do seu destino. Nestas circunstâncias, ainda há vantagens de realizar essas transações por meio dos intermediadores, pela sua experiência em adequar os serviços desejados a cada tipo de consumidor, e ao seu poder na aquisição de produtos e serviços a preços mais baixos. Cabe aos intermediários negociar outros itens necessários, incluindo transporte, guias, passeios e até refeições, que, juntos, formam o que se convencionou chamar de "pacote".

Enquanto os operadores turísticos elaboram programas de viagens, as agências vendem ao consumidor final, pois um operador não vende seus próprios programas diretamente ao público. As agências de viagem formam o nível intermediário da cadeia, entre os fornecedores e os consumidores finais dos serviços turísticos, pois são responsáveis basicamente pela organização e comercialização dos serviços prestados pelos fornecedores. O resultado é que operadoras e agências trabalham juntas no atendimento aos clientes.

Este trabalho buscou realizar uma avaliação sobre o papel desempenhado pelas agências e operadores turísticos e sobre a influência que estas exercem sobre os consumidores e seus comportamentos, quanto a escolha dos meios de hospedagens. Mais especificamente, buscou-se identificar qual o percentual de ocupações que é determinado pelas agências de turismo e operadores turísticos nos meios de hospedagem de Santa Catarina.

\subsection{Objetivo geral}

Investigar e refletir sobre a influência dos operadores turísticos e das agências de viagens na captação de hóspedes para os meios de hospedagens em Santa Catarina.

\subsection{Objetivos específicos}

Para tal investigação foram considerados os seguintes objetivos específicos: 
- Realizar um estudo bibliográfico sobre o papel atual das agências de viagens e operadores turísticos;

- Verificar a proporção de diárias faturadas em meios de hospedagens de Santa Catarina, através das agências e operadoras de turismo como intermediárias.

\section{DESENVOLVIMENTO}

No Brasil, o Instituto Brasileiro de Turismo (EMBRATUR) estabelece duas tipologias de intermediários turísticos no art. $4^{\circ}$ do Decreto 84.934/80: Agência de Viagens e Agência de Viagens e Turismo. Agência de Viagem é a empresa que, em geral, apenas comercializa produtos turísticos e atende diretamente o público consumidor. As Agências de Viagens e Turismo, por sua vez, têm a função de intermediar todos os serviços turísticos, permitindo o encontro da demanda com a oferta de serviços, além de prestar assistência turística aos viajantes ou turistas (MINISTÉRIO DO TURISMO, 2014). As agências de viagens e turismo, ou operadores de turismo, são aquelas cujos serviços estão ligados à operação da viagem, tendo como funções a contratação e execução de programas, roteiros e itinerários, quando estes fazem parte do pacote.

\subsection{As agências de viagens}

As agências de viagens são responsáveis pela intermediação e agenciamento de produtos e serviços relacionados ao turismo. Segundo Beni (2007) este tipo de empresa trabalha com pacotes turísticos, ou com produtos separados, ou personalizados, conforme o perfil de cada cliente, podendo atingir inúmeros segmentos, nichos de mercado e públicos diversos.

Sua atuação é de colaboração e interdependência em relação aos demais elementos que compõem a atividade turística, pois a viagem de turismo ocorre com a união de todos os seus componentes e não com os mesmos agindo de forma isolada (TOMELIN; TEIXEIRA, 2005).

Acerenza (1990, p. 28) define agência de viagem como a empresa que viabiliza a realização de viagens e outros serviços avulsos ou organizados em forma de pacotes, entre as empresas fornecedoras desses serviços e o usuário final, "[...] para fins turísticos, comerciais ou de qualquer outra natureza.". Esses serviços, segundo García Oro, Cruz Pérez, e Levya Velásquez (2009) dizem respeito às reservas de passagens, de alojamento e de programação de tours, aluguéis de carros e outros. Na mesma linha, Calderón (2012) considera a agência de viagem como o elo profissional entre o viajante e as empresas turísticas nacionais ou estrangeiras. Ainda segundo esse autor, essas empresas difundem as características interessantes e atraentes de um determinado local. Destas definições, compreende-se que uma agência de viagens atua como mediadora entre a pessoa que procura o serviço e o fornecedor de bens ou produtos turísticos.

García Oro, Cruz Pérez, e Levya Velásquez (2009) classificam as agências de viagens: a) de acordo com a natureza de suas vendas; b) de acordo com a atividade que realizam; c) segundo o tráfego de viajantes; d) de acordo com o produto ou mercado em que atuam. O Quadro 1 mostra a síntese desses autores. 
Quadro 1 - Tipologias de agências de viagem

\begin{tabular}{|c|c|}
\hline $\begin{array}{c}\text { De acordo } \\
\text { com a } \\
\text { natureza de } \\
\text { suas vendas }\end{array}$ & $\begin{array}{l}\text { Agências maioristas: organizam os serviços turísticos em "pacotes" para seu } \\
\text { oferecimento às agências minoristas, normalmente não oferecendo seus } \\
\text { serviços diretamente ao consumidor final. } \\
\text { Agências minoristas (ou agência detalhista), segundo Acerenza (1990): } \\
\text { oferecem ao consumidor o produto organizado por uma agência maiorista. } \\
\text { Não elaboram seus próprios produtos. Revendem viagens com roteiros } \\
\text { preestabelecidos tipo "pacotes" que são organizados por empresas } \\
\text { maioristas ou operadoras de turismo. } \\
\text { Agências maioristas-minoristas: combinam a possibilidade de ambas as } \\
\text { atividades. }\end{array}$ \\
\hline $\begin{array}{l}\text { De acordo } \\
\text { com a } \\
\text { atividade que } \\
\text { realizam }\end{array}$ & $\begin{array}{l}\text { Agências emissoras: se localizam onde estão as pessoas que têm intenção } \\
\text { de viajar. } \\
\text { Agências receptivas: estão localizadas aonde chega o turismo de massas. } \\
\text { Além de prestarem serviço para as operadoras de turismo (transfer, city } \\
\text { tour e assessoria ao turista enquanto ele estiver no destino da viagem), } \\
\text { elas próprias podem organizar e fornecer passeios e programas ao turista, } \\
\text { em uma relação comercial que não envolve as operadoras e agências que } \\
\text { vendem os pacotes. }\end{array}$ \\
\hline $\begin{array}{l}\text { Segundo o } \\
\text { tráfego de } \\
\text { viajantes }\end{array}$ & $\begin{array}{l}\text { Emissoras (outgoing): enviam viajantes a áreas geográficas distintas do } \\
\text { lugar onde se encontram. } \\
\text { Receptivas (incoming): atendem ou atraem turistas de outras regiões ao } \\
\text { lugar onde se localizam. } \\
\text { Emissoras-receptivas: organizam o tráfego turístico em ambos sentidos. }\end{array}$ \\
\hline $\begin{array}{l}\text { De acordo } \\
\text { com o } \\
\text { produto ou } \\
\text { mercado em } \\
\text { que atuam }\end{array}$ & $\begin{array}{l}\text { Produto: viagens de trabalho, pesquisa ou de férias. Inclui: trânsito, } \\
\text { facilidades, familiarização e têm como objetivos a difusão e incentivo de } \\
\text { serviços turísticos. } \\
\text { Mercado: estudantes, desportistas, famílias, pessoas solteiras, terceira } \\
\text { idade e recém-casados. }\end{array}$ \\
\hline
\end{tabular}

Fonte: Adaptado de García Oro, Cruz Pérez, e Levya Velásquez (2009).

As agências de viagem formam o nível intermediário da cadeia, entre os operadores turísticos e os consumidores finais dos serviços, pois são responsáveis basicamente pela organização e comercialização dos serviços prestados pelos fornecedores. O resultado é que as agências e as operadoras turísticas se completam no atendimento aos seus clientes.

\subsection{Operadoras de turismo}

No Brasil, as agências de viagens maioristas e os operadores de turismo se confundem, empregando as mesmas funções operacionais (TOMELIN, 2011). Porém, Acerenza (1990) explica que o operador de turismo opera seus próprios programas de viagens, com seus próprios equipamentos ou subcontratação de operadores terrestres locais. As agências maioristas, por sua vez, não operam seus próprios serviços. Note-se, ainda, que uma operadora de turismo vende seus produtos às agências detalhistas e diretamente ao público, através dos seus escritórios locais. 
Entretanto, as agências maioristas trabalham exclusivamente suas vendas por intermédio das agências detalhistas.

Segundo Petrocchi e Bona (2003) os operadores de turismo atuam como atacadistas, pois compram serviços em blocos e os revendem em pacotes menores. Na estruturação de um pacote, o operador não altera as características individuais de cada um dos serviços contratados, mas agrupa, formando um produto diferente e com maior valor agregado.

Os operadores de turismo contratam serviços de transporte, hospedagem, alimentação, lazer e outros complementares, integrando tudo em um pacote turístico, que é vendido direta ou indiretamente ao público consumidor (PETROCCHI; BONA, 2003). Em geral, os operadores colocam seus produtos para serem comercializados pelas agências de viagens ao consumidor final. As de menor porte, ou de alcance regional, vendem seus pacotes às agências ou diretamente ao público. Como adquirem produtos em quantidade maiores, os operadores obtêm descontos significativos e fora do alcance do cliente isolado - até mesmo das agências de viagens.

As grandes operadoras comercializam destinos e produtos de turismo de massa em larga escala e, portanto, seu preço é menor. As operadoras especialistas, por seu turno, adotam a estratégia de diferenciação e customização dos serviços às necessidades do cliente.

Operadores de turismo receptivo são operadores regionais que prestam serviços, principalmente aos operadores nacionais ou internacionais na área em que atuam. Estruturam os roteiros de visita às cidades onde têm base, como o city tour e o by night, além de roteiros pelas redondezas. Providenciam hospedagens e traslados, inclusive agendam restaurantes, teatros etc.

Porém, embora desempenhem papel importante na organização de viagens, as agências de viagem e os operadores de turismo disputam espaço com outras fontes de informação disponibilizadas via internet. $O$ e-Tourism se constitui em uma nova forma de turismo - o turismo eletrônico - e se utiliza da aplicação de tecnologias da informação e comunicação (TICs) em processos relacionados ao turismo, como a busca de informações e a compra de pacotes turísticos por viajantes.

O estudo de Buhalis e Law (2008) projeta a evolução futura do e-Tourism e demonstra mudanças críticas que irão influenciar a estrutura da indústria do turismo. Segundo esses autores, desde os anos 1980, as TICs têm transformado o turismo em todo o mundo. E, nos últimos tempos, a acelerada e sinérgica interação entre tecnologia e turismo trouxe mudanças fundamentais na indústria e em nossas percepções de sua natureza. O'Connor (1999 apud BUHALIS; LAW, 2008) observa que, cada vez mais, as TICs permitem que os viajantes acessem informações confiáveis e precisas, bem como realizem reservas em menor tempo, custo e inconveniência implicados por métodos convencionais.

As TICs também mudaram a eficiência e a eficácia das organizações de turismo, a maneira com que as empresas são conduzidas no mercado, bem como a maneira como os consumidores interagem com as organizações (BUHALIS, 2003). Segundo o Ministério do Turismo (2014), para o planejamento da viagem no período de 2013, menos de $10 \%$ dos turistas internacionais se utilizaram das agências de viagem como meio para o planejamento e organização de suas viagens ao Brasil, conforme se lê no Quadro 2.

Quadro 2 - Fontes de informações para organização da viagem

\begin{tabular}{|l|c|}
\hline Fonte de informação & $(\%)$ \\
\hline Internet & 37,0 \\
\hline Amigos e parentes & 27,2 \\
\hline Viagem corporativa & 18,4 \\
\hline
\end{tabular}




\begin{tabular}{|l|l|}
\hline Agências de viagens & $\mathbf{8 , 9}$ \\
\hline Guias turísticos impressos & 4,0 \\
\hline Feiras, eventos e congressos & 1,7 \\
\hline Folders e brochuras & 0,1 \\
\hline Outros & 2,7 \\
\hline
\end{tabular}

Fonte: Adaptado de Ministério do Turismo (2014).

Outro estudo do Ministério do Turismo (2014) revelou que, no período de 2013, a maioria dos estrangeiros $(69,2 \%)$ em viagem de lazer ao Brasil não utilizaram os serviços de intermediários (operadores de turismo ou agências de viagens), nem na compra de pacotes, tampouco noutros serviços avulsos, como mostra o Quadro 3.

Quadro 3 - Utilização de Agência de Turismo para viagem de lazer ao Brasil

\begin{tabular}{|l|c|}
\hline Pacote & $20,4 \%$ \\
\hline Serviços avulsos & $10,4 \%$ \\
\hline Não utilizou & $69,2 \%$ \\
\hline \multicolumn{2}{|c|}{ Fonte: Adaptado de Ministério do Turismo (2014). }
\end{tabular}

Em relação à Santa Catarina, as principais fontes de informações na escolha da capital Florianópolis como destino turístico no período de 2015 foram os comentários de amigos e parentes e o fato de já conhecerem o local. Neste ponto, foi nula a influência das agências de turismo na escolha (FECOMÉRCIO, 2015).

\subsection{0 turismo em Santa Catarina}

O Estado de Santa Catarina é reconhecido por suas potencialidades turísticas, principalmente, devido à sua natureza exuberante. O Estado abriga praias, fontes de águas termais, dunas, cânions, serras e campos naturais; constituindo, assim, uma variedade de diferentes paisagens que servem para o desenvolvimento de diversas formas do turismo de lazer, que vão desde o ecoturismo, passando pelo turismo rural, incluindo o turismo voltado para esportes radicais.

Os meios de hospedagem também são bastante diversificados e vêm buscando seguir e se adequar às especificidades de cada região do Estado. Na região da Serra Catarinense, concentramse os hotéis fazenda, localizados em áreas rurais; nos centros de comércio e industriais encontramse os hotéis voltados para atender a demanda de negócios e eventos. O maior número de estabelecimentos de lazer está concentrado na faixa litorânea, próximos às praias. As regiões de Imbituba, Porto Belo e o Sul da llha de Santa Catarina são as que apresentam maior número de pousadas. Já nas cidades de Florianópolis, Itapema e Balneário Camboriú, além dos hotéis de lazer, se concentram os três maiores resorts do Estado: o Resort \& Spa Costão do Santinho, localizado na Praia do Santinho, Norte da llha de Santa Catarina; o Infinity Blue Resort Spa, na Praia dos Amores, em Balneário Camboriú; e o Plaza Itapema Resort \& Spa, em Itapema (SANTOS, 2012).

Ainda que concentrado nos grandes centros urbanos, o turismo de negócios e de eventos também vem ganhando relevância no cenário turístico e econômico de Santa Catarina. No entanto, é na alta temporada de veraneio que o turismo se constitui em uma importante fonte 
econômica para SC e, devido as suas praias, concentram-se as maiores demandas turísticas de lazer.

Segundo as estimativas da SANTUR (2014), na alta temporada de verão (dados de fevereiro de 2014), o Estado recebeu um fluxo de 1.894 .405 turistas (ver Quadro 4), desse montante, 89\% brasileiros e $11 \%$ estrangeiros, especialmente argentinos e uruguaios (ver Quadro 6).

Quadro 4 - Movimento estimado de turistas em Santa Catarina

\begin{tabular}{|l|r|r|r|}
\hline Origem & \multicolumn{1}{|c|}{ Fev. 2012 } & \multicolumn{1}{|c|}{ Fev. 2013 } & \multicolumn{1}{c|}{ Fev. 2014 } \\
\hline Nacionais & 2.148 .863 & 1.662 .910 & 1.683 .460 \\
\hline Internacionais & 167.752 & 93.066 & 210.945 \\
\hline Total & $\mathbf{2 . 3 1 6 . 6 1 5}$ & $\mathbf{1 . 7 5 5 . 9 7 6}$ & $\mathbf{1 . 8 9 4 . 4 0 5}$ \\
\hline
\end{tabular}

Fonte: SANTUR (2014).

Como se lê no Quadro 4, o turismo catarinense é predominantemente doméstico, recebendo em fevereiro de 2014 - mês de alta temporada turística - um fluxo nacional de 1.683 .460 com uma variação negativa de $27,65 \%$ em relação a 2012 e positiva de $1,22 \%$ em relação a 2013, apontando uma tendência para a retomada do crescimento no fluxo interno.

Quadro 5 - Principais emissores nacionais

\begin{tabular}{|l|r|r|r|}
\hline Estado & Fev. 2012 & Fev. 2013 & Fev.2014 \\
\hline Santa Catarina & $42,29 \%$ & $43,97 \%$ & $35,10 \%$ \\
\hline Rio Grande do Sul & $27,11 \%$ & $22,29 \%$ & $32,36 \%$ \\
\hline Paraná & $15,15 \%$ & $20,30 \%$ & $19,59 \%$ \\
\hline São Paulo & $9,37 \%$ & $9,13 \%$ & $7,73 \%$ \\
\hline Rio de Janeiro & $2,03 \%$ & $1,67 \%$ & $1,64 \%$ \\
\hline
\end{tabular}

Fonte: SANTUR $(2012,2013,2014)$

O turismo catarinense recebeu turistas dos mercados emissores, conforme se vê no Quadro 5, em sua maioria da Região Sul do País.

Quadro 6 - Principais emissores internacionais

\begin{tabular}{|c|c|c|c|}
\hline País & Fev. 2012 & Fev. 2013 & Fev.2014 \\
\hline Argentina & $69,56 \%$ & $79,06 \%$ & $80,58 \%$ \\
\hline Uruguai & $9,24 \%$ & $6,97 \%$ & $6,31 \%$ \\
\hline Paraguai & $7,61 \%$ & $3,10 \%$ & $5,83 \%$ \\
\hline Chile & $3,80 \%$ & $3,87 \%$ & $3,40 \%$ \\
\hline Alemanha & $1,09 \%$ & $0,77 \%$ & $0,97 \%$ \\
\hline
\end{tabular}

Fonte: SANTUR $(2012,2013,2014)$

Santa Catarina é o Estado da Região Sul privilegiado devido belezas naturais e da sua diversidade de atrativos. Consequentemente, o turismo neste Estado é beneficiado devido à proximidade com os principais Estados brasileiros emissores - Rio Grande do Sul e Paraná - bem como o principal país emissor, a Argentina, o que se pode constatar observando os Quadros 5 e 6. 


\section{A CONSTRUÇÃO DA PESQUISA}

Inicialmente buscou-se conhecer a realidade das influências de operadores e agências de turismo na ocupação de meios de hospedagens em Santa Catarina, com a finalidade principal de elaborar um instrumento baseado nas experiências reais. Para este procedimento, utilizamos a pesquisa exploratória, através do método survey.

\subsection{Procedimentos metodológicos}

Theodorson e Theodorson (1970) conceituam o termo pesquisa exploratória como "estudo exploratório: um estudo preliminar do principal objetivo é familiarizar-se com um fenômeno a investigar, de modo que o maior estudo a seguir pode ser projetado com maior compreensão e precisão". Inicialmente foi selecionado um número expressivo de meios de hospedagem, aproximadamente 540, das principais cidades turísticas de Santa Catarina, dos quais o contato foi viabilizado por intermédio da Associação Brasileira da Indústria de Hotéis (ABIH) de Santa Catarina. Através do envio de e-mails, e contatos telefônicos, convidamo-los a participarem da pesquisa através do preenchimento do questionário on-line, durante o período de janeiro a outubro de 2015, ao mesmo tempo em que explicamos a importância da pesquisa para o setor. A expectativa era de que as respostas seriam enviadas dentro de um mês, no máximo, pelos respondentes. Recebemos como retorno, o preenchimento do questionário por apenas 21 meios de hospedagens, dos quais, realizando uma triagem nos dados, 11 precisaram ser descartados, devido a informações incompletas ou inexistentes.

Com uma amostra de 10 meios de hospedagens, realizamos análises estatísticas não conclusivas devido ao tamanho da amostra, mas que resultaram em um estudo preliminar sobre a influência das agências e operadores de turismo no Estado, no ano de 2014. Os dados foram coletados no período compreendido entre junho e agosto de 2015.

A Figura 1 apresenta os tipos e quantidades de meios de hospedagens constituintes da amostra.

Figura 1 - Tipos e número de meios de hospedagens da amostra.

\section{Distribuição dos tipos de meios de hospedagens}

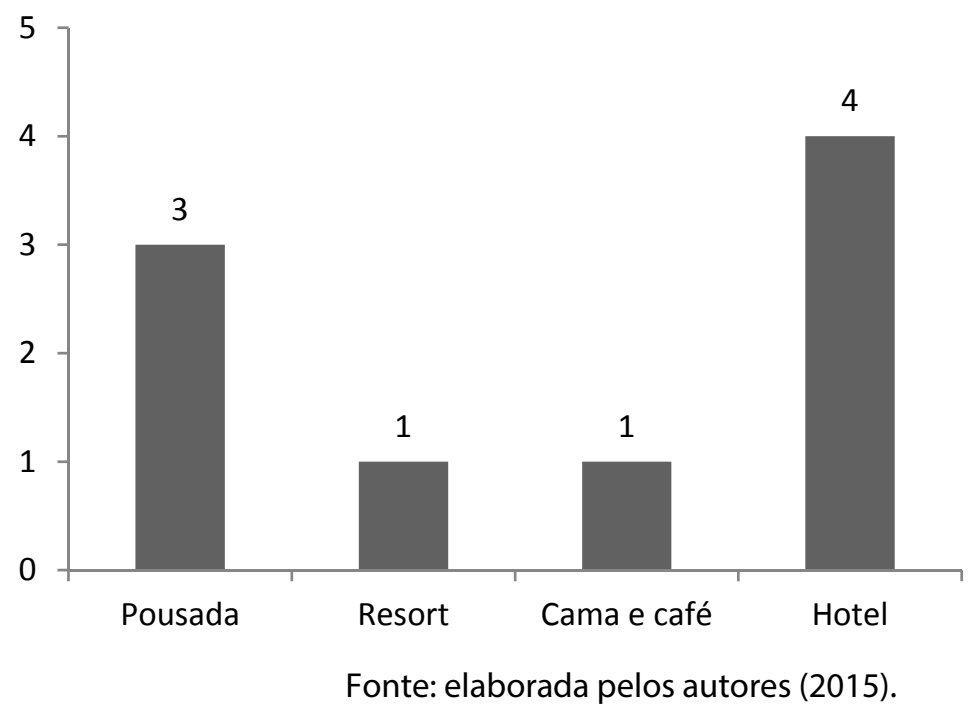

Quantidade 


\subsection{Caracterização da pesquisa}

A metodologia abordada nesta pesquisa caracteriza-se como exploratória e descritiva, uma vez que aplica a estatística para a análise dos dados provenientes de um levantamento de dados na investigação de um assunto específico. A pesquisa possui também caráter bibliográfico, uma vez que esta traz uma investigação relacionada ao tema em diversos artigos.

\subsection{Análise dos dados e resultados}

Com base na planilha originada a partir da coleta de dados, foram investigadas as origens das diárias faturadas em 2014, entre: diárias faturadas via operadoras turísticas; agências de viagem; serviços de reserva on-line; serviço de reserva via site do meio de hospedagem; reserva realizada diretamente no meio de hospedagem, sem utilização do site do estabelecimento e diária faturada sem reserva anterior.

Desta forma, apuramos um total de 49.814 diárias faturadas pelos meios de hospedagens analisados.

Figura 2 - Origens das diárias faturadas nos meios de hospedagens em 2014.

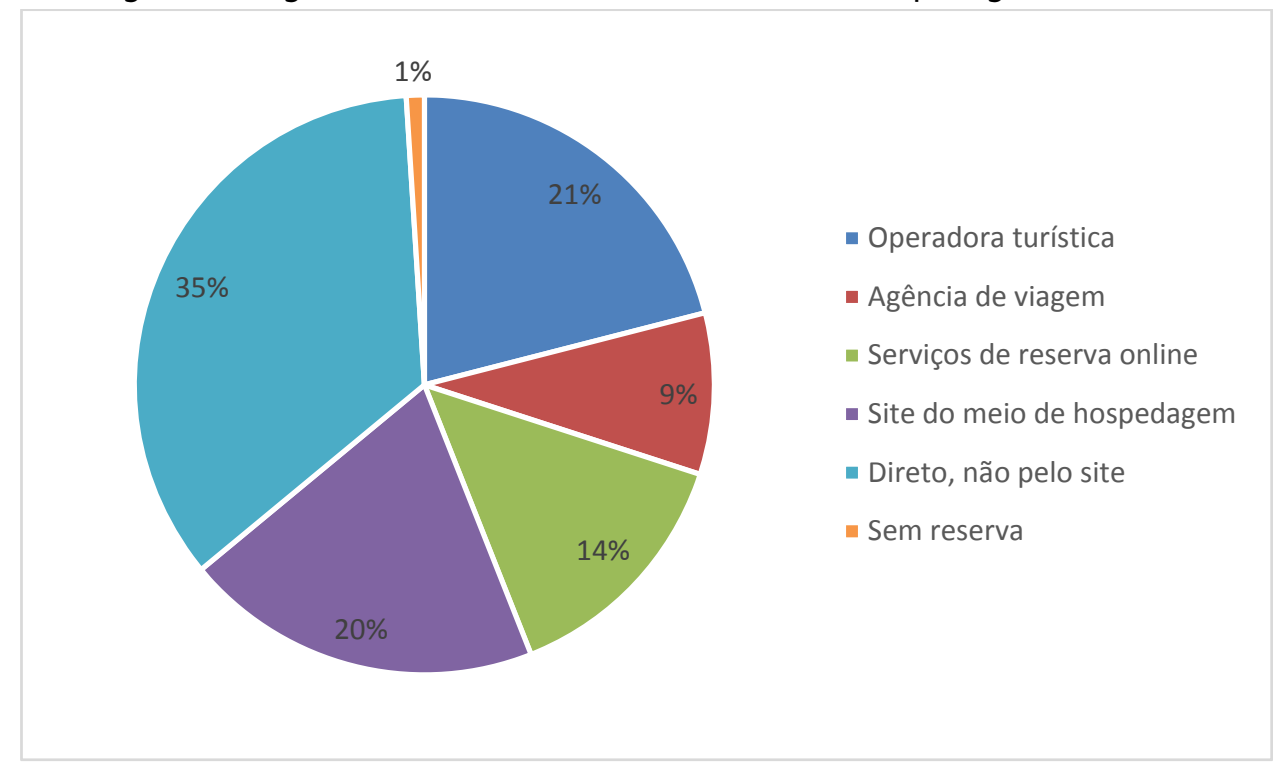

Fonte: elaborada pelos autores (2015).

Podemos observar na Figura 2 que, em geral, a maioria das diárias faturadas neste período foi proveniente de reservas realizadas diretamente no meio de hospedagem. Se somarmos as parcelas de diárias que foram faturadas através do site do hotel ou sem reserva prévia, temos que mais da metade das diárias faturadas foram reservadas sem a utilização de nenhum intermediário, incluindo as agências e operadoras. As diárias faturadas nestes meios de hospedagens via agência de viagem ou operadoras turísticas somam $30 \%$.

Repetimos a análise, desta vez avaliando as reservas faturadas segundo os meios de hospedagens: hotel, pousada e resort (Figura 3). 
Figura 3 - Origens das diárias faturadas em 2014

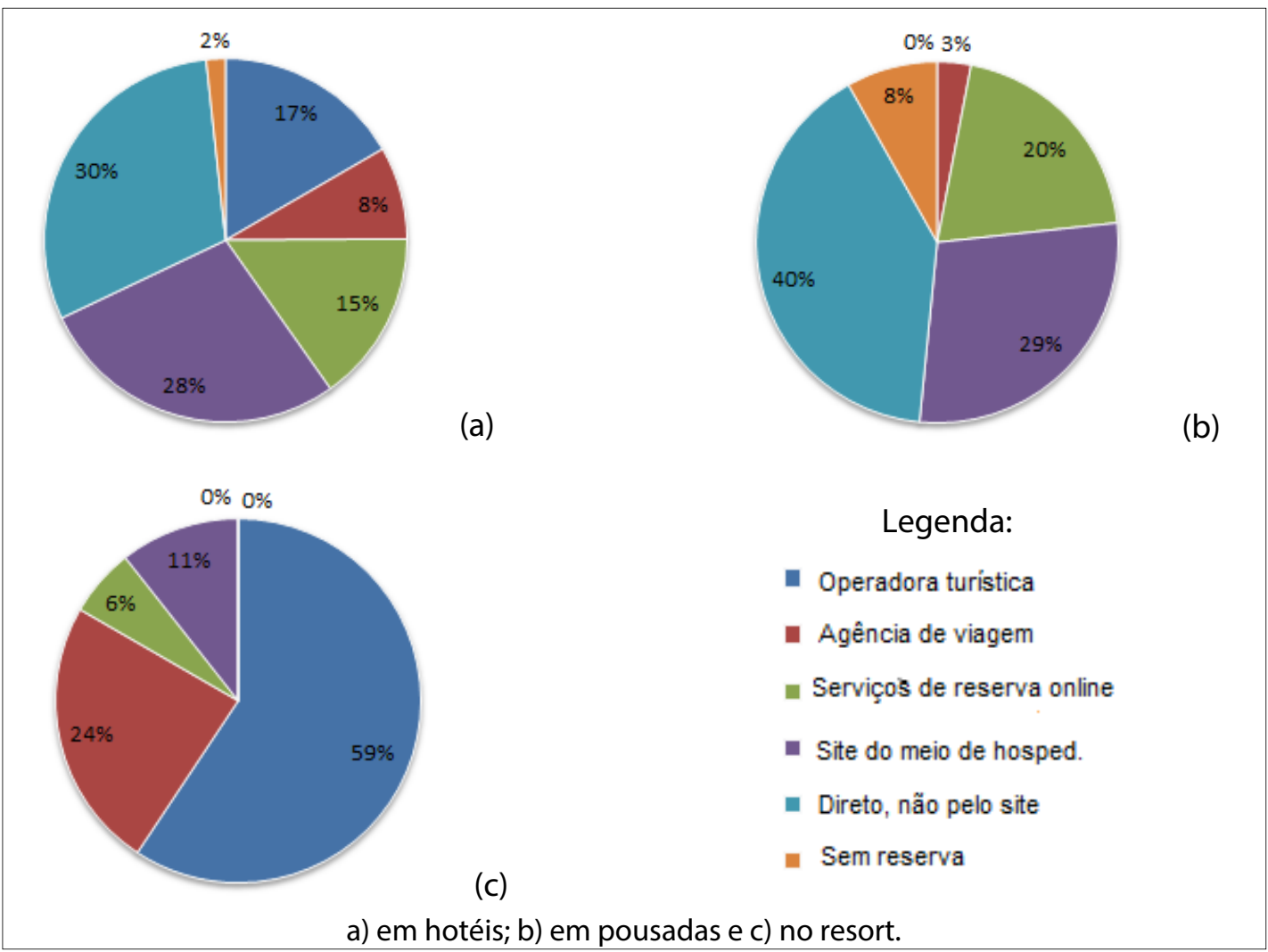

Fonte: elaborada pelos autores (2015).

Em geral, predominam a ocupação originada de reservas realizadas diretamente no meio de hospedagem, ou a partir do site próprio do estabelecimento. Esta análise nos sugere que a influência das operadoras é nula e a das agências de viagem baixa, para a ocupação das pousadas (Figura 3-b). No entanto, esta influência é significativa para os hotéis (Figura 3-a) e fundamental para a ocupação no resort (Figura 3-c), onde as ocupações através das operadoras turísticas representaram mais da metade do faturamento e através das agências, a quarta parte do faturamento.

\section{CONCLUSÃO}

O presente trabalho reuniu informações referentes ao papel das agências e operadoras turísticas em Santa Catarina, bem como as classificações destas quanto a diferentes aspectos. A intenção inicial do trabalho foi de realizar uma pesquisa em maior escala, com resultados seguramente representativos da realidade. Infelizmente, e apesar de vários esforços realizados, a representatividade da amostra de meios de hospedagens no Estado foi insuficiente para análises conclusivas, devido à baixa adesão por parte destes no preenchimento do instrumento de coleta de dados - questionário. Este ponto foi um causador de limitação da pesquisa. No entanto, consideramos este como um dos resultados analisados e importante para o seguimento das pesquisas no setor no Estado. Relacionamos a baixa adesão à pesquisa ao desconhecimento da importância desta para o desenvolvimento de ferramentas de gestão para o setor e também ao receio por parte dos gerentes ou proprietários em fornecer informações que consideram estratégicas para o negócio. A maioria dos meios de hospedagens de Santa Catarina localizam-se na faixa litorânea do Estado e, historicamente, desenvolveram-se a partir de negócios familiares, 
em razão da oportunidade diante do constante e crescente turismo na região. Desta forma, sugerimos que a tradição da gestão familiar de muitos meios de hospedagens se sobreponha ao interesse em estudo para outras formas de gestão.

Apesar de limitada, a amostra constituinte de hotéis, pousadas, cama e café e um resort possibilitou reflexões preliminares quanto à influência das agências e operadoras turísticas na ocupação dos meios de hospedagens no Estado. A análise geral dos meios de hospedagens ratifica as análises do Ministério do Turismo, de que é baixa a representatividade das agências e operadoras nas reservas dos meios de hospedagens em Santa Catarina. Os hóspedes optam em maioria por realizar as reservas através do site ou diretamente no meio de hospedagem. No entanto, realizando a análise para cada tipo de meio de hospedagem, percebemos que a influência destes intermediários é praticamente nula para as pousadas, mas significativa para os hotéis e fundamentais no caso do resort analisado. Obviamente as análises não são conclusivas, mas sugerem que, em geral, o papel das agências e operadoras turísticas pode estar sendo subestimado na região, devido a uma análise geral que inclui pousadas e outros meios de hospedagens de menor porte. Esta análise preliminar requer trabalhos futuros, com amostras representativas dos meios de hospedagens da região, para cada tipo de meio de hospedagem. Para tanto, esperamos que este trabalho incentive uma maior participação dos meios de hospedagens para a realização de estudos sobre o tema em trabalhos futuros.

\section{REFERÊNCIAS}

ACERENZA, M. A. Agencias de Viajes, Organización y Operación. México: Trilhas, 1990.

BENI, M. C. Análise estrutural do turismo. 12. ed. São Paulo: Senac, 2007.

BUHALIS, D. eTourism: information technology for strategic tourism management. [2003].

Disponível em: <http://goo.gl/HNCPcb>. Acesso em: 15 mar. 2015.

BUHALIS, D.; LAW, R. Progress in information technology and tourism management: 20 years on and 10 years after the Internet - The state of eTourism research. Tourism Management, v. 29, n. 4, p. 609-623, 2008.

CALDERÓN, M. de L. S. Estructura y administración de agencias de viaje. México: Redercer Milenio S.C., 2012.

FECOMÉRCIO. Pesquisa Fecomércio de Turismo - Turismo de Verão em Florianópolis 2015. Núcleo de Pesquisas Fecomércio SC. [2015]. Disponível em <http://www.fecomerciosc.com.br/fmanager/fecomercio/pesquisas/arquivo395_1.pdf>. Acessado em: 30 mar. 2015.

GARCÍA ORO, E.; CRUZ PÉREZ, M.; LEVYA VELÁSQUEZ, N. La agencia de viajes una empresa importante y poco conocida dentro del sector turístico actual. TURYDES - Revista de investigación em turismo y desarrollo local, v. 2, n. 6, 2009. Disponível em: <http://www.eumed.net/rev/turydes/06/opv.htm>. Acesso em: 20 mar. 2015. 
GOSSON, G. A. O. et al. Influência dos intermediários de distribuição de produtos turísticos no processo de decisão do meio de hospedagem pelo consumidor. Tourism \& Management Studies, Penha, Portugal, v. 10, n. 2, p. 123-232, 2014.

MINISTÉRIO DO TURIMOS. Estudo da Demanda Turística Internacional - 2013. [2014]. Disponível em: <http://www.dadosefatos.turismo.gov.br/dadosefato s/demanda_turistica/internacional>. Acesso em: 10 dez. 2014.

PETROCCHI, Mario; BONA, André. Agências de Turismo: planejamento e gestão. Clementina, SP: Futura, 2003.

SANTOS, F. M. Geografia das redes hoteleiras: mundo, Brasil e santa Catarina. [2012]. Tese (Doutorado em Geografia) - Universidade Federal de Santa Catarina, Florianópolis.

SANTUR. Programa de promoção do turismo catarinense. Ação: estudos e pesquisa de turismo Estudo da demanda turística 2012. [2012]. Disponível em: <turismo.sc.gov.br>. Acesso em: 20 mar. 2015.

SANTUR. Programa de promoção do turismo catarinense. Ação: estudos e pesquisa de turismo Estudo da demanda turística 2013. [2013]. Disponível em: <turismo.sc.gov.br>. Acesso em: 20 mar. 2015.

SANTUR. Programa de promoção do turismo catarinense. Ação: estudos e pesquisa de turismo Estudo da demanda turística 2014. [2014]. Disponível em: <turismo.sc.gov.br>. Acesso em: 20 mar. 2015.

THEODORSON, G. A.; THEODORSON, A. G. A modern dictionary of sociology. London: Methuen, 1970.

TOMELIN, C. A. Mercado de agências de viagens e turismo: como competir diante das novas tecnologias. São Paulo: Aleph, 2001.

TOMELIN, C. A. Gestão da cadeia de suprimentos e serviços no subsistema de agências de viagens e turismo de Santa Catarina. 2011. Tese (Doutorado em Administração e Turismo) Universidade do Vale do Itajaí, Biguaçu.

TOMELIN, C. A.; TEIXEIRA, A. H. Gerenciamento da cadeia de suprimentos e do marketing de relacionamentos nas agências de viagens. In: TRIGO, L. G. G et al. Análises Regionais e Globais do Turismo Brasileiro. São Paulo: Roca, 2005. p. 685-709. 